\title{
ACTOS DEVOCIONALES Y ENFERMEDAD: ENCARNACIÓN DEL MILAGRO EN EL NUEVO REINO DE GRANADA DURANTE EL SIGLO XVIII
}

\author{
DEVOTIONAL ACTS AND DISEASE: INCARNATION OF THE MIRACLE \\ IN THE NEW KINGDOM OF GRANADA DURING THE CENTURY XVIII
}

\author{
Lina Marcela Silva Ramírez*
}

\begin{abstract}
Este artículo analiza los actos devocionales alrededor de la enfermedad ocurridos en el Nuevo Reino de Granada, colonia americana del Imperio español, con sede en Santafé de Bogotá durante el siglo XVIII como resultado de un proceso material y espiritual apoyado en la retórica promovida por la Iglesia católica, en la que se empezó a manifestar la definición de los límites y clasificación de los milagros. Se identificaron las principales referencias descritas en las relaciones o diarios de viaje escritos por clérigos de diferentes órdenes que transitaron por las provincias con fines misionales. La metodología se orientó desde una mirada popular (como un hecho inesperado) y territorial de los milagros y se determinaron tres momentos relevantes: la apropiación de las milagrosas imágenes en los territorios, los actos de fe asociados a las cualidades atribuidas a los santos y el establecimiento del cuerpo como territorio privilegiado del milagro por medio de las disposiciones de la religiosidad para la asistencia de la enfermedad. histórica.

Palabras clave: historia del milagro, prodigio, actos devocionales, Nuevo Reino de Granada, religiosidad popular, teología
\end{abstract}

This article analizes the devotional acts surrounding the illnesses that occurred in the New Kingdom of Granada. This American colony belonging to the Spanish Empire was based in Santafé de Bogotá during the XVIII century. This resulted from a material and spiritual process supporting the rhetoric promoted by the Catholic Church which manifested the definition of the limits and the classification of miracles. They identified the main references described in the writings and travel diaries written by clerics of different orders who traveled through the provinces for missionary purposes. The methodology was oriented from a popular view, something unexpected and territorial view of the miracles. It determined three relevant moments: the appropriation of miraculous images in the territories, the faith acts associated to the qualities attributed to the saints and the establishment of the body as privileged territory of the miracle through dispositions of the religiosity for the assistance of the illness.

Key words: History of miracle, prodigy, devotional acts, Nuevo Reino de Granada, popular religiosity, historical theology.

\section{Introducción ${ }^{1}$}

Durante los siglos XVI al XVIII en el Nuevo Reino de Granada, colonia americana del Imperio español con sede en Santafé de Bogotá, se produjeron numerosos sucesos sobrenaturales inexplicables, catalogados como milagros, que fueron utilizados por la Iglesia católica como instrumentos para la propagación de la fe y que encontraron eco en los rituales de adoración existentes entre las poblaciones indígenas y negras. En algunos casos estos hechos fueron la base de conversiones de caciques o indios que presenciaron e hicieron parte de milagros o que ofrecieron promesas a los santos a cambio de mejoras en cuanto a su salud, condiciones naturales, entre otros asuntos que parecían imposibles ${ }^{2}$.

Este artículo presenta un análisis de algunos actos devocionales y su relación con el discurso del milagro. La cultura espiritual se asume aquí como el conjunto de elementos que aluden al establecimiento y continuidad de las creencias en una sociedad determinada y cuya principal característica es la inmaterialidad.

Así como lo plantea Le Goff al referirse a la noción de lo maravilloso, dichos elementos contemplan las denominadas "herencias culturales", las actitudes que los individuos tienen frente a ellas, su funcionalidad y los roles que tienen dentro del sistema religioso; por tanto, la cultura espiritual recoge elaboraciones fijadas como imaginarios y representaciones que constituyen un capital simbólico fundado en las creencias y la fe, el que se ve reflejado en las formas de compresión de la realidad que circulan entre las comunidades. Por su parte, la cultura material alude a la cristalización de los discursos en pautas comportamentales o de

\footnotetext{
* Corporación Universitaria Minuto de Dios, Bello, Colombia. Correo electrónico: 1silvaramir@ uniminuto.edu.co
} 
intercambio y transacción que, en algunos casos, conducen a la legitimación de un poder (institucionalizado o no) que las administra u objetualiza por medio de signos, como en el caso de las imágenes veneradas y de las milagrosas imágenes.

La asimilación de la cultura espiritual en el Nuevo Reino de Granada se tradujo en la recepción de leyendas alrededor de santos, vírgenes o mártires que las órdenes religiosas impregnaron a la sensibilidad de los pobladores; la transmisión de estas historias dejó un registro en las recopilaciones y hagiografías, género que logró un gran despliegue en la península ibérica y que llegó de manera tardía al territorio neogranadino donde tuvo gran circulación como libros impresos durante el siglo XVIII ${ }^{3}$.

Aunque varios de estos textos aparecen bajo la autoría de "anónimos", la mayoría de ellos se escribieron resaltando las cualidades de ciertas advocaciones de la virgen ${ }^{4}$ o los testimonios de su aparición, renovación y prodigios y los declarantes generalmente eran testigos directos que entregaban sus versiones a la pluma de los interesados en abonar el terreno para la santificación; en este sentido, los testimonios registrados llevan consigo la impronta de la apropiación que la fe tuvo en los pueblos y la dinámica de producción de lo santo. Independiente de su aprobación o no por parte de la institución eclesiástica, las órdenes religiosas cumplieron un papel importante en la instauración de imaginarios, devociones y sentimientos de identidad afincados en la institucionalización del milagro.

Para definir y describir la construcción de lo milagroso se tomó como punto de partida los planteamientos de Le Goff, al observar que lo maravilloso cristiano se cristaliza en el milagro que en realidad reduce lo maravilloso:

a) porque lo remite a un solo autor: Dios

b) porque lo reglamenta: control y crítica del milagro.

c) porque lo racionaliza: el carácter imprevisible, esencial de lo maravilloso, es sustituido por una ortodoxia de lo sobrenatural.

Frente a lo milagroso, lo mágico (por más que se distinga entre magia negra y blanca) se inclina por lo sobrenatural ilícito o engañoso, de origen satánico, diabólico. Entre ambos, se desarrolla un mundo maravilloso que es neutro, tolerable para el cristianismo pero que en realidad procede de un sistema precristiano tradicional que se refiere al folklore, aun cuando ya haya sido recuperado por la cultura erudita (Le Goff 199:19).

En el Nuevo Reino de Granada la segregación a la que alude Le Goff se hace evidente mediante la reglamentación y la necesidad de control de las prácticas rituales de los indígenas, así como en las vías de reconocimiento de los hechos sobrenaturales que empiezan a requerir de un procedimiento que finalmente conduce al paso del ámbito espiritual al ámbito jurídico.

De manera más concreta, la noción de sensibilidad religiosa plantea la existencia de unas formas en las que se manifestó la creencia, casi todas a nivel material; así, la elección de los santos, sus milagros y su presencia en la vida de los neogranadinos encuentra su representación en las prácticas devocionales, testimonios y celebraciones. Así, a pesar de los cambios en la significación de lo que implicó el milagro para la sociedad del Nuevo Reino de Granada; lo maravilloso, lo sobrenatural y lo admirable también hicieron parte del despliegue de lo sagrado que trajo consigo el proceso colonizador, ya fuera por contemplación, persecución o institucionalización.

\section{Las milagrosas imágenes: riqueza material y espiritual}

El discurso del milagro fue una referencia para las órdenes religiosas que llegaron al Nuevo Reino de Granada, ya que por intermedio de las misiones y los actos públicos se alcanzaba el logro más importante para la empresa evangelizadora: la conversión. La estructura de las narraciones milagrosas se presentó fundamentalmente como una remembranza de los fundadores y como una forma de promover los principios de dichas órdenes, gracias a las prácticas como los sacramentos, las novenas, las fiestas o sermones. Entre estas prácticas se destacó la solicitud e instalación de imágenes como conmemoración; estas se convirtieron, a su vez, en un "artificio" que materializó la memoria para los feligreses.

La mediación se dio con la construcción de una memoria y transmisión del "milagro inicial" mediante actos que muchas veces fueron en contra de las disposiciones eclesiásticas y que generó 
conflictos con las autoridades civiles e incluso con los primeros arzobispos como fray Juan de los Barros, fray Luis Zapata de Cárdenas y Bartolomé Lobo Guerrero que buscaron en los sínodos una orientación más precisa de la Iglesia respecto de estas prácticas 5 .

A pesar de esto, la salvación de las almas continuó siendo la motivación de franciscanos, dominicos y recoletos de San Agustín y San Francisco, comunidades que se mencionan en los archivos y textos consultados como protagonistas en la protección de imágenes, profusión de santos, conservación de reliquias y fabricación de santuarios, altares e iglesias en sitios lejanos a las ciudades (ver Tabla 1). Así, la promoción de las figuras milagrosas ocurrió durante varios años, pues su intención era lograr una permanencia en el tiempo y en la mentalidad de los nativos y el principal medio para alcanzar este objetivo fue el uso de la pintura (retablos, lienzos) y la propaganda de la devoción.

La veneración de las imágenes consistía en el mantenimiento de las buenas condiciones físicas, estimular las cofradías, el rezo de novenas u oraciones específicas como salves y rosarios para las vírgenes, sacarlas a procesiones en festividades establecidas por el calendario cristiano y para adoración colectiva; y, en cuanto fuese posible, levantar iglesias dedicadas a ellos; así, por ejemplo, se identifica la participación de las órdenes en la veneración de las imágenes aunque en muchos de estos casos no se registran claramente los hechos milagrosos y solo se hace referencia a su fama dentro de las poblaciones.

La colocación de imágenes de santos taumaturgos, como la de San Gregorio realizada por los capuchinos en Carolina del Darién en 1786 (AGN Legajo 121, Folio 1017R); la aparición de la virgen de la Concepción en Ocaña en 1793; y la pervivencia de los cuerpos de los mártires en las iglesias, como el caso del mártir Francisco Javier en el templo de San Ignacio de Santafé, son los ejemplos más claros.

Entre los clérigos que escribieron para notificar los aspectos de la vida civil y religiosa del Nuevo Reino de Granada se encuentra Basilio Vicente de Oviedo, quien relaciona las riquezas en las jurisdicciones de Tunja, Santafé, Vélez, la villa de Nuestra Señora de Leiva, San Gil, Pamplona, Neiva, Honda, entre otras ciudades y villas, incluyendo el territorio de Mérida y Barinas.

De Oviedo, perteneciente a los dominicos, aporta una lectura de las condiciones sociales del siglo XVIII. A modo de inventario, sus relatos recopilan elementos importantes para la riqueza eclesiástica que vincula lo material con lo espiritual.

Tabla 1. Comunidades religiosas y santos venerados en la zona central del Nuevo Reino de Granada.

\begin{tabular}{llll}
\hline \multicolumn{1}{c}{ Comunidad religiosa } & \multicolumn{1}{c}{ Santo/Advocación } & Localización & \multicolumn{1}{c}{ Clasificación } \\
\hline San Agustín & N.S. de Altagracia & Santafé & Bulto \\
& N.S. de Borotare & Borotare & Bulto \\
& N.S. de Belén & Valle de Chámeza & Pintura en lienzo \\
& Cristo de Choachí & Choachí & Bulto \\
\hline San Francisco & N.S. de Monguí & Monguí & Pintura en lienzo \\
& San Diego & Mariquita & Cuadro \\
\hline Santo Domingo & N.S. del Rosario de Chiquinquirá & Chiquinquirá & Pintura \\
& Santo Ecce Homo & Vélez & Cuadro \\
& Virgen & Popayán & Cuadro \\
& Verónica & Santafé & Cuadro \\
\hline Recoletos de San Agustín & NS de la Candelaria & Entre Villa de Leiva y Tinjacá & Cuadro \\
& NS de la Popa & Cartagena & Bulto \\
& Niño Jesús & Tunja & Bulto \\
\hline Recoletos de San Francisco & NS del Campo & Santafé & Imagen de Piedra
\end{tabular}

Elaboración propia.

Fuentes: Juan Flórez de Ocaríz, Genealogías del NRG; Basilio Vicente de Oviedo, Cualidades y Riquezas del Nuevo Reino de Granada; fray Alonso de Zamora, Historia de la provincia de San Antonio del Nuevo Reino de Granada. 
El número de feligreses, el diezmo, los tributos, la limosna, la cantidad de monjas y su tipo de velo, son algunos de los elementos en los que centra su informe $\mathrm{y}$ aunque su interés central no son precisamente los hechos milagrosos, reconoce en las imágenes y en la asistencia de los santos un gran capital espiritual, al punto de ubicarlos como variables que inciden en su catalogación de los curatos (De Oviedo 1930).

Si se retoma la hipótesis de Julia Costilla en la que plantea que "los milagros pueden actuar como herramientas simbólicas esgrimibles estratégicamente desde distintos sectores y actores de la sociedad para generar mecanismos de cohesión social, acceder a ciertos espacios y beneficios o legitimar posiciones" (Costilla 2010:36), es posible argumentar que la fuerza de las reformas borbónicas dio lugar a un reconocimiento de dicho capital espiritual como un factor que impulsó y orientó una percepción de estos sucesos como factores importantes que definían un orden social fundamentado en la dinámica religiosa, así como lo evidencian los relatos de De Oviedo.

En su descripción de las cualidades y riquezas, el clérigo identifica la presencia de imágenes milagrosas en algunos curatos, la mayoría de ellos ubicados en la jurisdicción de Tunja. Incluye también los datos de las comunidades religiosas asociadas a estos referentes sagrados y su establecimiento como "patronos", las visitas de los feligreses y algunas fiestas que tuvieron gran convocatoria. También enuncia la existencia de imágenes como reliquias. Allí es posible inferir que el uso de esta categoría no corresponde a lo que generalmente se entendía como tal $^{6}$ y que centra su atención en lo que se consideraban reliquias insignes, esto es, "la cabeza, brazo o capilla de algún Santo" (RALE 1731).

De Oviedo habla de las reliquias de Santa Bárbara en Santa Bárbara de las Nieves (Tunja) de la cual solo dice que "es una estatua de maravilloso primor" (De Oviedo 1930:120), la imagen de Nuestro Señor Jesucristo crucificado en el pueblo de Sátiva (Tunja) -que visitan los peregrinos y dicen ser milagrosa- y, por último, "una hechura de Jesús Nazareno muy linda y un Santo Cristo aparecido en una piedra, bien perfecto" (De Oviedo 1930:162) en la ciudad de Vélez. La reliquia a la que otorga mayor relevancia es la de Nuestra Señora de Belén que permanecía en la hacienda de Belén, jurisdicción de Tunja. Además de tener la condición de milagrosos, algunos de los santos que se consideraban reliquias eran reconocidas como "patronos" de las poblaciones como el caso de San Judas Tadeo en el pueblo de Tópaga (Tunja) o San Roque en el pueblo de Caguán (Neiva); respecto de ellos De Oviedo destacaba las romerías de las provincias.

De igual forma, los curas se beneficiaban de estas prácticas, ya que era mayor el número de misas solicitadas por los fervorosos devotos y, por tanto, se incrementaban las ganancias para la Iglesia, de allí la importancia de la organización de santuarios u oratorios en las haciendas. Acerca de San Roque, por ejemplo, señala el autor que a pesar de pertenecer a la jurisdicción de Neiva y de la Villa de la Purificación, de la Plata y de Timaná, "dicen serle lo más útil al cura del Caguán, pues de esas misas solo pueden tener al año 500 pesos el cura" (De Oviedo 1930:241).

Los milagros atribuidos a estas imágenes inventariadas tenían un estrecho vínculo con las grandes advocaciones que habían llegado al Nuevo Reino de Granada en el siglo XVI; incluso esta conexión se realizaba para incluir signos fundacionales de santuarios y conventos. Así ocurrió con Nuestra Señora de la Candelaria que hace presencia en una peña de la Villa de Leiva entre los ermitaños descalzos de San Agustín, en el que "provino sacar licencias y fundar dicho convento que promovió muchísimo el señor Arzobispo Lobo Guerrero. Tiene una hermosa imagen de NS de la Candelaria y es muy visitada de los fieles, porque experimentan su favor con muchos milagros" (De Oviedo 1930:158).

En consecuencia, las reliquias (objetos), sumadas a una advocación (creencia instituida o sustituida) y alimentadas por un imaginario (fama de las obras y favores), eran fundamentales para delimitar el milagro. Este proceso se complementaba con la actualización de las leyendas existentes a una escala local ya fuese por la apropiación de historias o por la renovación de las mismas, lo que implicaba que el santo realizara una obra sobrenatural en la que proyectaba una gracia o don concedido por la fuerza divina.

De los cinco relatos planteados por De Oviedo acerca de milagrosas imágenes, tres se relacionan con la advocación de Nuestra Señora del Rosario, ellas son:

a. Nuestra Señora del Rosario de Chiquinquirá. Para el siglo XVIII, época en la que De Oviedo produce su texto, la Virgen de Chiquinquirá es reconocida por su renovación milagrosa ocurrida en 1586, pues gracias a los esfuerzos de los dominicos su leyenda se difundía en los sitios 
cercanos. Como lo menciona el sacerdote, esta imagen se renovó "por virtud divina el 26 de diciembre de 1586, entre las ocho y nueve de la mañana, manifestándose a su devota sierva María Ramos, para el mayor bien o asilo de este Nuevo Reino, con los continuos milagros y maravillas para bien y beneficio de los cristianos que la invocan" (De Oviedo 1930:121). Esta imagen fue significativa para la sociedad del Nuevo Reino de Granada. Al ser delegada su orientación a los dominicos, esta fue trasladada a Santafé donde permaneció por un tiempo; sin embargo, su fama era tal que hacia 1643 el Cacique de Chiquinquirá, llamado Mateo, solicitó su retorno al considerar que aquella ciudad se la había apropiado. Tal petición se puso en consideración de los capitulares, quienes después de consultar a los competentes y de acordar el pago de limosnas atrasadas, procedieron a acordar su devolución (AHRB legajo 16, folio 189 R-190 R).

b. Nuestra Señora de Monguí en Tunja. También era visitada por numerosos fieles "devotos de todo el Reino y aun de los Prelados y magnates de Santafé, como son señores Oidores, etc." ( De Oviedo 1930:123). La copia de este cuadro fue enviada por fray Francisco Antonio Vélez Ladrón de Guevara al virrey; De Oviedo profundiza en el origen de esta imagen, cuyo debate estaba entre haber sido fabricada por el rey Carlos V de un color moreno (por referencia a los indios que habitaban en la zona) o haber sido traída por Felipe II de Inglaterra.

c. La tercera es una imagen similar a la de Chiquinquirá que se renueva en el pueblo de Labateca (Pamplona). Este caso se relaciona con una renovación milagrosa de un lienzo en Pamplona, imagen similar a la de Chiquinquirá: "Por esta maravilla es muy frecuentado de peregrinos en romería aquel sagrado santuario, en que los fieles alcanzan favores particulares de la Soberana y Clementísima Señora (...) las frecuentes romerías de los fieles, pueden rentarle al párroco 1000 pesos" (De Oviedo 1930:189).

Otro de los relatos se relaciona con la advocación de Los Dolores (la virgen del Topo en Muzo) y la última habla de San Jacinto, patrón de la Iglesia de Santo Domingo en la jurisdicción de Tocaima. En estos relatos es posible observar la construcción de referentes (imágenes, advocaciones) que nutrían el campo religioso y operaban como ejes del desarrollo de otras leyendas. De otro lado, los lienzos fueron un material muy constante en las historias referidas, y esto condujo al cuestionamiento de los materiales usados en su producción; muchos de ellos, al ser nombrados como milagrosos, pasaban a ser revisados por expertos españoles que tenían el conocimiento para definir si los cambios eran o no una auténtica renovación?.

Por otra parte, la aparición de Nuestra Señora del Topo en su advocación de la Virgen de los Dolores ocurrió en la ciudad de Muzo, entre los pueblos de Itoco, Quipama y Topo; aunque fue llevada "a la ciudad de Santafé y se colocó con grandísima decencia y veneración en una grandiosa capilla, en la iglesia catedral, donde por su medio obra mi Señor muchos milagros y maravillas en beneficio de los fieles, que cada vez que se experimenta alguna necesidad o epidemia o falta de aguas, acuden con novenas a su patrocinio y al instante le siguen el remedio de la fuente de sus misericordias" (De Oviedo 1930:277).

El texto también relata el acontecimiento sobrenatural efectuado por otra imagen, esta vez de San Jacinto en Tocaima. De nuevo los religiosos de Santo Domingo aparecen mencionados como parte de la narración y dice el sacerdote que

...se cuenta como por tradición que
habiendo inundado el Bogotá, que allí
llaman Patí, con una horrenda creciente en
castigo de cierta blasfemia que profirió un
vecino de allí muy rico, llamado don Juan
Díaz, que teniendo una casa muy grande
y opulenta, toda con el dueño la anegó
y arrebató, y que habiéndose llevado la
creciente entre las demás casas la imagen
de San Jacinto, fue después hallada mucho
trecho distante de la ciudad, colocada
sobre una viga de las que arrebató el río
(De Oviedo 1930:250).

Este último caso identificado en la obra abordada encuentra eco en un expediente que reposa en el Archivo General de la Nación de Colombia y en el que es posible considerar que la valoración de esta imagen no fue solo espiritual. El pleito fue registrado ante las autoridades civiles y corresponde a la solicitud realizada por el señor Lázaro Monroy en 1746, quien presenta la petición ante el capitán don 
Salvador de Trujillo, alcalde de la ciudad, del santo que le ha sido quitado argumentando un mal uso de las limosnas que ha pedido con él. Allí aparecen las voces de varios testigos: el maestre de campo José Manuel Perdomo de Betancur, los vecinos de la ciudad Manuel Herrera y Tomás de Castro quienes manifiestan que la imagen pertenece a Lázaro Monroy y que las limosnas pedidas "se han hecho bajo licencia de los prelados de Santo Domingo a quienes ha entregado la limosna que recogió" (AGN $\mathrm{T} 22$, folios 727-729 R); es así como la presencia de las imágenes de los santos movilizaba también la esfera social y económica, pues poseer la imagen también era símbolo de riqueza material.

Tanto en el caso del cacique Mateo como en el de Lázaro Monroy, las limosnas serían un punto clave en la identificación de los intereses que movilizaban el intercambio entre la cultura material y espiritual. Así, la pobreza que era reconocida y situada como "voto" de algunas comunidades religiosas, fue también un instrumento de control sobre las dádivas a los santos milagrosos ${ }^{8}$; el imaginario católico operaba entonces mediante la fe y desembocaba en el control de los recursos económicos.

A fines del siglo XVIII el milagro mantenía su esencia cohesiva. Frente a esto, acontecimientos o sucesos de tipo prodigioso tendían a posibilitar la participación de comunidades religiosas o la formación de las mismas y las poblaciones emergieron como agentes de las creencias y devociones. La imagen continuó siendo el principal medio retórico por el que se difundían las posturas eclesiásticas aún con la oposición del protestantismo que catalogaba estos actos como superstición y adoración.

Como un aporte a la difusión de las manifestaciones de religiosidad popular, la dilatación del poder, la oposición a las reformas, incluso la compleja situación de pobreza y las condiciones naturales (desastres, enfermedades) crearon un escenario propicio para la consolidación del discurso del milagro.

\section{Los actos de fe y la diversidad de los rituales}

Las sensibilidades religiosas de los pobladores del Nuevo Reino de Granada estuvieron marcadas por el dinamismo religioso y por la diversificación de las formas rituales. Así, las demostraciones de afecto, rogativas, promesas y celebraciones a los santos se convirtieron en un punto de partida clave, ya que conectaron los ámbitos espiritual, social y económico.

La respuesta de los pobladores ante la propaganda milagrosa se consignó como registro en los archivos civiles que los presentan como videntes o sujetos de un hecho. La veneración fue una de las prácticas más difundidas por la Iglesia católica en el proceso de instauración del milagro; los actos que respondían al reconocimiento del valor de las imágenes por parte de los pueblos en el siglo XVI son una muestra de ello, pues más importante que "imponer" una figura, bulto o reliquia, era el reconocimiento que esta podría tener en los conversos, $\mathrm{y}$, en el caso de que la conversión fuera reciente, el registro cobraba mayor relevancia.

Esto se evidencia en el caso de los pueblos de indios mencionados por De Tovar y Buendía al relatar el viaje que realiza la imagen de la Virgen de Chiquinquirá desde esta población hasta Tunja, cuando los feligreses piden a la Justicia, Cabildo y Regimiento que traigan la milagrosa imagen a dicha ciudad para aliviar los padecimientos de las epidemias de sarampión y viruela.

Indica De Tovar y Buendía que antes de la salida de la milagrosa imagen se acercó a la capilla de Chiquinquirá el indio Diego, cacique de Tinjacá, con muchos otros indios principales y ofreció una promesa en limosna para que dicha imagen pasara por su pueblo. También asistieron al lugar el cacique de Chiquinquirá y su gente para solicitarle al cura que no se llevara a la Virgen. En cuanto a la veneración de la imagen en dicho tránsito el autor narra las diferentes muestras de devoción como postrarse de rodillas, herirse en el pecho, llorar, besar la tierra, entre otras, "demostraciones todas que causaron tierna admiración a todos cuantos las vieron, por ser tan recién convertidos, y no tener pleno conocimiento de nuestra santa Fe Catholica" (De Tovar y Buendía 1735:45).

En el relato de De Tovar y Buendía acerca de la recepción de esta milagrosa imagen en los pueblos se mencionan algunas de las muestras devocionales ya instauradas por la fe católica. Así, en el pueblo de Tinjacá "se le cantó el salve y Letanías, y se le hizo una rogativa, a que asistieron los indios con mucha devoción, gemidos y lágrimas" (De Tovar y Buendía 1735:46); por su parte, en el pueblo de Suta, donde reconocían sus milagros "le profesaban mucha devoción que manifestaron en la ostentación con que salieron a recibirla, más de una legua fuera del pueblo, con Cruz alta en procesión y con tantas 
luces que aviendo cerrado al noche, no se echaban menos las del sol" (De Tovar y Buendía 1735:47). Ocurrió de manera similar en Sáchica donde los indios acompañados del cura llevaron la imagen hasta la iglesia y le cantaron la Salve y Letanías.

De acuerdo con lo planteado por Michel de Certeau frente a la relación de la oración con el cuerpo, aquella se encuentra ligada a los gestos e implica una imposición del sentido y un reconocimiento de los símbolos que la comprenden, en tanto que "para no ser mágico el gesto solicita la palabra, que lo convierte en un llamado o en una recolección" (De Certeau y Goldstein 2007:38)

Así como el sacrificio, la devoción o la divinidad se manifestaban en el cuerpo de los mártires, los prodigios que estos religiosos podían obrar con sus propias manos y que transmitían "la gracia divina de Dios" incluían actos físicos como tocar las partes del cuerpo afectadas (la cabeza), ungir o dar de beber. Esta situación es visible incluso en el acto de la liturgia en el que Marion reconoce "un espectáculo que convoca y, eventualmente, colma la vista, pero también el oído, el olfato, el tacto e incluso el gusto. Efectúa todas las estéticas posibles y puede así parecer el espectáculo total" (Marion 2006:117). Así, aunque el principal sentido que se identifica en la apreciación de estos sucesos era la vista, existían otros casos en los que sentidos como el tacto o el olfato ampliaban la experiencia perceptiva del milagro. El acto colectivo de ver implicaba un vínculo directo con la creencia y aunque en muchas ocasiones las imágenes o devociones fuesen impuestas, eran necesarios ciertos sucesos también inexplicables que afirmaran la presencia de las advocaciones o generaran vínculos con las poblaciones evangelizadas.

Jean-Luc Marion sostiene que la visión debe ser entendida como un "don hecho a unos ojos que no lo esperan" y que, por tanto, ver es recibir, puesto que aparecer es dar (se) a ver. Desde aquí es posible considerar que la idea de lo milagroso se constituyera como testimonio, ya que "lo visible se da a ver. No se trata todavía de revelación, sino que se trata de lo que, eventualmente, deberá quizás soportar más tarde el peso de la gloria infligido por la revelación" (Marion 2006:87).

Para el dilatado territorio del Nuevo Reino de Granada, fray Juan de Santa Gertrudis menciona la existencia de estos testimonios desde el siglo XVII como un instrumento indispensable para el destierro de las supersticiones, observancias y agüeros en el caso de los indígenas del valle del Sibundoy, muchos de estos involucraban experiencias corporales relacionadas con santos. Este religioso cuenta cómo específicamente en Mocoa (curato de padres dominicos) tuvo presencia un Cristo al que le llamaron el Zambo, por su color moreno y cuya veneración nace a partir de una experiencia física en la que se intentó mudar al pueblo, pero al llevar la imagen este retornó en cuatro ocasiones inexplicablemente a la iglesia antigua. Al observar lo ocurrido los indígenas lo vigilaron

y al apuntar el alba vieron al Señor que se venía por sus pies, y uno de ellos le dio un macanazo en el hueso de la pierna, tal como si hubiera sido de carne le quedó el golpe con un gran cardenal señalado hasta el día de hoy. El Señor, recibido el golpe, se volvió atrás, y se volvió a su iglesia nueva, obedeciendo a los indios. Dieron ellos cuenta al cura, y éste visto el prodigio, dio cuenta a su superior. Se divulgó el caso y se mandó llevar al Señor a Quito, donde está con mucha veneración (De Santa Gertrudis, 1569).

Varios elementos se rescatan del relato anterior: el primero tiene que ver con las cualidades corporales atribuidas en este caso a Cristo, cuyo color moreno indica una caracterización física de la imagen. La experiencia corporal de este prodigio empieza por la observación del color de su piel y de las similitudes que llevan a asignarle un sobrenombre: "el zambo". La vista vuelve a ser el sentido privilegiado en el momento en el que, al amanecer, observan que el Señor se aproxima caminando y busca por cuarta vez el camino de retorno a la iglesia antigua; uno de ellos lo golpea en el hueso de la pierna causándole un trauma.

La expresión "tal como si hubiera sido de carne" indica la magnitud del prodigio y dicho golpe, señalado con un gran cardenal queda como vestigio, evidencia y testimonio de lo ocurrido. Es así como a partir de una experiencia sensible que vincula el tacto -y por supuesto el dolor- los indígenas reportan ante el cura el caso de la obediencia de este cristo mediada por el castigo.

Las manifestaciones de la experiencia de la fe se conectan con la fabricación autóctona de reliquias en la que está presente la relación con la tierra y el agua. Dentro de las muestras devocionales 
De Tovar y Buendía también menciona la relación de los indios con las "reliquias"; en este mismo recorrido de la Virgen por los diferentes pueblos quedan registrados actos como la recolección de gotas de la cera que la alumbraba, así como el "arraigo" producido -y nombrado de esta manera-que produjo después del milagro de sanar a una gran cantidad de personas en Tunja de las pestes mencionadas. Dicho arraigo se materializó en la producción de estampas y retablos con su retrato que estuvieron posteriormente en las iglesias para recordar que por medio de ella los indios alcanzaron "la sanidad de sus cuerpos y reparación de sus almas" (De Tovar y Buendía 1735:53).

Estas manifestaciones de devoción tuvieron inicialmente un impacto territorial, porque esas actitudes de los fieles permitieron configurar el lugar como "santificado"; así, las demostraciones de veneración incluyeron las visitas o peregrinajes a la "casa de la Madre de Dios" y la generación de un nuevo sentido al lugar del milagro, situación que se afianzó con la construcción de la iglesia. Acerca de esto De Tovar y Buendía relató:

En demostración de la veneración, en que tenían aquel lugar, comenzaron a sacar tierra de él, y estimándola por reliquia, con Fe y esperanza, de que con ella obraría la Madre de Dios prodigios, la prevenían triaca, aplicándola por remedio de cualquier enfermedad $[\ldots]$ con esta tierra experimentaran el premio de su devoción en grandes, y milagrosos efectos, los que usaban de ella por medicina: como también con el agua muy clara y dulce, que comenzó a manar a distancia de este santo lugar poco menos de una vara: en el cual, quedó desde entonces una celestial botica, donde se halla por medicina tierra y agua, muy eficaz contra todo género de males, de fiebres pestilentes, dolores agudos de costado, flujos de sangre, llagas, apostemas, heridas, picaduras de culebras ponzoñosas, incendios, tormentas; y finalmente, para todo tan provechosa, como se ha experimentado, y se podrá reconocer de los muchos milagros (De Tovar y Buendía 1735:76).

El uso de la tierra sacada del lugar no solo fue en relación con la enfermedad. De Tovar y Buendía también menciona que en las procesiones anuales que realizaban los habitantes de pueblos aledaños como Villa de Leyva, Fúquene, Susta, Simijaca, Saboyá, Tinjacá y Ráquira, se extraía este elemento "para deshacerla en agua y regarla en sus tierras de labor, para que se fertilicen y den frutos" (De Tovar y Buendía 1735:78), uso que por su fama de milagroso se extendió en otras partes del Nuevo Reino de Granada, al Reino de Perú y a la provincia de Quito.

Una transición importante que se pudo identificar es el paso de esta fabricación de reliquias naturales al contacto humoral que desprendían los santos. En los Archivos de San Luis Beltrán (Bogotá) y en el Archivo General de la Nación reposan dos casos en los que las personas "vieron sudar lienzos". El primero ocurrió en Mariquita en el año 1620 cuando don Juan de Borja (capitán general del reino encargado de la conquista de indios panches y pijaos), quien a su paso de Ibagué a Mariquita, el 13 de noviembre presenció que "estando en la función religiosa de esa noche los circunstantes comentaron que la pintura del señor San Diego principió a sudar agua en el rostro y no cesaba, aun cuando los fieles la enjugaban con algodones, pañuelos" (ASLOP índice 1188, Vols. 1-3, folio 0025R). Unas horas después de que el escribano diera fe de este hecho, aparentemente se detuvo y el cuadro secó, pero con la llegada de otras personas curiosas el milagro ocurrió de nuevo. Del acontecimiento dio fe el escribano real don Alonso de Hurtado y Arias, después de cerciorarse de lo ocurrido hacia las 9 de la noche, luego cesó, pero "volvieron a notar, pasada algunas horas, volvió a repetirse el milagro, pero con admiración, pues sudaba agua y sangre".

El segundo caso registrado en el año 1712 corresponde a la sudoración de un cuadro de la madre Francisca, religiosa profesa del convento de carmelitas descalzas, que fue testificado por el calificador del santo oficio de la Inquisición José Chinchilla y que narró de la siguiente manera:

...al llegar a ver el retrato de dicha madre Francisca reconocí iba cayendo, por la rodilla del retrato, a modo de sudor en cantidad, el cual limpié. A cuyo tiempo llegó el padre don Pedro de la Rosa y el maestro don Luis de Mancilla, presbíteros, $\mathrm{y}$ vieron si pudiera ser agua derramada por otro efecto trató; y no viéndole, dejaron a la providencia divina lo que pudiera ser. Discurriendo, al parecer, que era milagro 
(...)así mismo certifico que dicho retrato, que conservo en mi casa para mi consuelo y por el buen crédito de sus famosas virtudes, expedido de muchas personas pobres de esta ciudad, en sus necesidades sin poder excusarme a sus repetidas súplicas y fervor con que le aclaman, y así llevan dicho retrato para alivio de ellas, principalmente para partos dificultosos en que se ha notado tener particular patrocinio, en cuya conformidad y por ser todo lo que aquí refiero cierto y verdadero[...] (AGN T. 63 folios 489 R -490 R).

Tanto en el cuadro de la madre Francisca como en el de San Diego las cualidades corporales eran relevantes, ya que daban "vida" al objeto material; muchas veces las enfermedades eran asociadas a la falta de pureza del alma y, aun en su lecho de muerte, la santidad podía reconocerse porque de sus cadáveres no se desprendiera ningún tipo de olor o se perfumara con aromas.

Otras de las imágenes famosas en el Nuevo Reino de Granda por desprender sudores maravillosos fueron el Cristo de Ubaté ubicada en la iglesia del pueblo de indios que llevaba este mismo nombre, Nuestra Señora de Roque Amador situada en el altar mayor del Monasterio de Predicadores de la ciudad de Tunja, cuyo bálsamo era famoso entre los pobladores, y el cuadro de la Verónica situado en el pedestal del tabernáculo del Santo Cristo en la capilla del convento de Santo Domingo en Santafé9.

\section{Actos devocionales y enfermedad: el cuerpo como territorio privilegiado del milagro}

La afirmación del milagro en el Nuevo Reino de Granada tuvo como territorio privilegiado el cuerpo de los devotos. Este fenómeno ocurrió por la prevalencia de un orden popular en la forma de interpretar los sucesos inesperados. Así, los hechos relacionados con la curación que antes no se consideraban determinantes de la santidad cobraron relevancia y las vidas ejemplares cada vez fueron más anónimas para los pobladores de las provincias que vieron en las imágenes una alternativa a sus dificultades.

Bajo esta perspectiva, la población privilegió la invención y circulación de las curaciones milagrosas conforme aumentaron los casos relatados y la transmisión de los mismos entre los pobladores, la fama de los milagros se incrementó y el uso de la fe se trasladó de la figura a los objetos con gran facilidad. Dos elementos sustentaron esta relación (figura-objeto): el primero fue el ideal de salvación que se encontraba como base en las leyendas milagrosas y que le dio al cuerpo un lugar importante como vía de sanación; el segundo fue la afirmación del cuerpo como un territorio privilegiado para el milagro de curación.

Respecto del ideal de salvación, dentro del territorio neogranadino circuló información acerca de la relación alma-cuerpo en casos de enfermedad. Las Recetas de Espíritu para Enfermos del Cuerpo, escritas por el padre jesuita Pedro de Mercado, proponían la relación con los santos como una forma de encontrar alivio y socorro ante los padecimientos. El texto, publicado en 1680 para el Hospital San Juan de Dios, fue un manual de 45 recetas que proponía la fortaleza del alma como un medio para asimilar el dolor mediante un ejercicio místico donde los santos constituían un modelo a imitar.

En las recetas 35 a 38 el padre propone a los enfermos la búsqueda de las enfermedades que padecieron los santos para consolarse y les sugiere encomendarse a ellos y acompañarse de imágenes de la Virgen María y de Cristo dolorido, así como la gratitud constante a estos y a Dios por medio de alabanzas. De igual manera, en la receta 42, Mercado propone que "el enfermo no ha de querer más la salud que la enfermedad", porque, por una parte, debía aceptar la voluntad divina sobre la humana (su propia voluntad de sanarse); y, por otra, el enfermo debía comprender que salud y enfermedad eran designios de Dios igualmente buenos.

Estas divulgaciones se relacionaban estrechamente con las disposiciones arzobispales frente al trato de los enfermos por parte de los médicos, porque en el primer sínodo realizado por fray Juan de Barrios se hicieron extensivos los primeros controles relacionados con la "cura de las almas". En el capítulo 6 de estas constituciones sinodales de 1556 se estableció "que los médicos amonesten a los enfermos que curen sus almas"; así, antes de proceder a la cura de los cuerpos los médicos debían llamar a quienes podían confesar y comulgar "porque muchas veces la enfermedad corporal procede de la espiritual y curada esta da Dios salud al cuerpo" (Romero 1960: 483). Además, se les prohibiría el ingreso a la iglesia a los médicos que no acogieran este decreto. 
El segundo elemento que sustentó la afirmación del cuerpo como un territorio privilegiado y favoreció la proliferación de actos devocionales fue la difusión de un santoral con el que se hacía frente a la enfermedad; de esta manera, mediante esta asignación de facultades curativas los santos se presentaron como abogados ante la enfermedad.

Según lo propone el manual del padre Mercado existía un santoral dispuesto a interceder por el enfermo en tres niveles en los que se les podía invocar: el primero de ellos era el de asistencia que debía hacerse hacia los santos médicos Cosme y Damián y el santo enfermero Juan de Dios (De Mercado 2006:19). El amparo de estos se invocaba cuando el médico que curaba al enfermo realizaba su visita, pues, según se describe en la receta 5, con dicha asistencia se evitaban los errores humanos involuntarios en el tratamiento. A ellos debía pedírseles "que den luz al Médico para que conozca su enfermedad, y que le alcancen de Dios acierto, para que receten las medicinas convenientes" (De Mercado 2006:20) o, en el caso de Juan de Dios, para que acompañara la aplicación de los remedios.

Explica Mercado que la confianza no debía ponerse en los médicos que curan sino en los santos médicos, "porque aún en esta vida, cuando las enfermedades eran de peligro, y faltaba el arte de la Medicina, ocurrían a Dios por medio de la oración, y haciendo la señal de la cruz sobre los enfermos, les daban la salud. Por lo cual ahora, que están en el cielo, alcanzarán de Dios el acierto para los Médicos si el enfermo se lo pide" (De Mercado 2006:21).

El segundo nivel de invocación se realizaba a los santos enfermos a quienes se pedía el socorro de la paciencia y la resignación y de quienes se esperaba la compasión. El padre Mercado dedica la receta 35 a este atributo, según esta, "el enfermo ha de procurar noticias de las enfermedades que padecieron los santos, para consolarse, para pedirles socorro y para imitarlos" (De Mercado 2006:139). La imitación de los santos como modelo para asumir los padecimientos se justificaba en el sentido de identidad creado a partir del dolor; por ello, "tener noticia" implicaba conocer la historia y las formas en que cada santo afrontaba su condición; de esta manera, la invocación realizada se entablaba desde un vínculo que se suponía efectivo porque ellos habían sufrido la misma dolencia durante su vida en la tierra. Más que la conmiseración se buscaba la emulación de la vida de estos santos enfermos (ver Tabla 2) en cuanto al buen modo en que padecían sus dolencias. La intención y la voluntad del enfermo debía ser la de comprender su martirio del mismo modo en que lo hacía el santo sin presentar quejas ante la voluntad divina.

Tabla 2. Santos enfermos para invocar.

\begin{tabular}{|c|c|}
\hline Enfermedad & Santo \\
\hline Apoplexia & $\begin{array}{l}\text { Santa Gertrudis (Religiosa) } \\
\text { San Francisco de Salés (Obispo de Génova) }\end{array}$ \\
\hline Asma & $\begin{array}{l}\text { V. Beda } \\
\text { Santa Rosa de santa María }\end{array}$ \\
\hline $\begin{array}{l}\text { Baldíos y } \\
\text { dolores } \\
\text { de cabeza }\end{array}$ & $\begin{array}{l}\text { San Francisco Xavier } \\
\text { San Chrisóstomo } \\
\text { Santo Domingo Loricato } \\
\text { Santa Lidubina }\end{array}$ \\
\hline Calenturas & $\begin{array}{l}\text { San Juan Chrisóstomo } \\
\text { San Teodoro Estudita } \\
\text { Santa Rosa de Santa María } \\
\text { Santa Teresa de Jesús }\end{array}$ \\
\hline $\begin{array}{l}\text { Dolor de } \\
\text { costado }\end{array}$ & $\begin{array}{l}\text { San Paulino Obispo } \\
\text { San Mauro Abad }\end{array}$ \\
\hline Desmayos & $\begin{array}{l}\text { San Chrisóstomo } \\
\text { Santa Gorgonia (Hermana de San Gregorio } \\
\text { Nazianzeno) }\end{array}$ \\
\hline Estómago & $\begin{array}{l}\text { San Gregorio papa } \\
\text { San Bernardo } \\
\text { San Teodoro Estudita } \\
\text { Santa Catalina (Hija de Santa Brígida) }\end{array}$ \\
\hline Fístola & Santo Tomás \\
\hline Gota & $\begin{array}{l}\text { San Gregorio papa } \\
\text { San Julián (Mártir de Alejandría) } \\
\text { San Bonito Obispo } \\
\text { San Francisco de Borja }\end{array}$ \\
\hline Hipocondría & Santa Rosa de Santa María \\
\hline Hidropesía & $\begin{array}{l}\text { Santa Lidubina } \\
\text { Benjamín Monge }\end{array}$ \\
\hline Llagas & $\begin{array}{l}\text { San Daniel Estilita } \\
\text { San Simeón Estilita }\end{array}$ \\
\hline Muelas & $\begin{array}{l}\text { Santa Polonia } \\
\text { San Francisco de Borja }\end{array}$ \\
\hline Narices & Beato Bartolo (Tercera orden de San Francisco) \\
\hline Ojos & $\begin{array}{l}\text { San Francisco } \\
\text { Santa Lugarda }\end{array}$ \\
\hline Perlesía & $\begin{array}{l}\text { San Sérvulo } \\
\text { Santa Rómula }\end{array}$ \\
\hline
\end{tabular}

Elaboración propia.

Fuente: Mercado, Pedro de., Estela Restrepo Zea. Recetas De Espíritu Para Enfermos Del Cuerpo Por El P. Pedro De Mercado De La Compañía De Jesús, Bogotá, Universidad Nacional de Colombia, 2006. 
Tabla 3. Santos abogados.

\begin{tabular}{ll}
\hline \multicolumn{1}{c}{ Enfermedad } & \multicolumn{1}{c}{ Santo } \\
\hline $\begin{array}{l}\text { Calenturas continuas } \\
\text { Dolor de hijada y riñones } \\
\text { Mordeduras de perros rabiosos, }\end{array}$ & San Gil \\
serpientes y víboras & San Zoylo \\
Ojos, vista & Santa Quitenia \\
Dientes y muelas & Santa Luzía \\
Ahogos de garganta & Santa Polonia \\
Mal de los pechos & San Blas \\
Bubas y llagas & Santa Águeda \\
Peste y Landre & San Lázaro \\
\hline
\end{tabular}

Elaboración propia.

Fuente: Mercado, Pedro de., Estela Restrepo Zea. Recetas De Espíritu Para Enfermos Del Cuerpo Por El P. Pedro De Mercado De La Compañía De Jesús, Bogotá, Universidad Nacional de Colombia, 2006.

Finalmente, el tercer nivel de invocación propuesto en las recetas era hacia los santos abogados. Estos se proponían como intercesores ante Dios para librar a los hombres de enfermedades específicas. A partir de ello se configuró un santoral (ver Tabla 3) ofrecido a disposición de los enfermos, en el que se propagaba la devoción como parte de la cultura espiritual de la época y se encontraba en los dolientes un terreno propicio para fomentar las peticiones por la salud. Aunque estas fueron numerosas, la regulación de las mismas tuvo también un sitio en las orientaciones brindadas a los enfermos para la cura del alma y del cuerpo; así lo evidencia la receta 44 del padre De Mercado que le otorga una condicionalidad a las peticiones.

En este sentido, la enfermedad era entonces una oportunidad física para la salvación del alma mediante la búsqueda de la virtud, y los padecimientos del cuerpo eran la manifestación de las enfermedades del alma que en muchos casos se olvidaban. Estos podían ser del orden del entendimiento (distracciones y malos pensamientos) o del orden de la voluntad (amores desordenados y odios ilícitos, tibiezas y resfríos del espíritu) además de otros que no se sentían o identificaban con facilidad (De Mercado 2006:200). Por tanto, los dolores físicos se asociaban a males espirituales y morales. Al respecto expresaba el padre De Mercado: "Ay males efpirituales de inmodeftia en los ojos, de efcuchar murmuraciones en los oídos, de gula en el paladar, de malas palabras en la lengua, de malos paffos en los pies, de malas obras en las manos y otros achaques que no tienen número" (De Mercado: 201).

Como se ha abordado a lo largo de este texto, es posible concluir que las formas espirituales promovidas por la Iglesia católica en el Nuevo Reino de Granada durante el período colonial fueron objeto permanente de disputa. En este sentido, la funcionalidad del milagro no fue únicamente propagandista ${ }^{10}$ porque a esta se sumó una de tipo cohesiva en tanto que condujo al fortalecimiento de organizaciones sociales al establecer el espíritu devocional entre sus integrantes. De otra parte, las figuras milagrosas (imágenes o personalidades) se instalaron como referentes de las mismas y la espera del milagro también pasó a ser una condición colectiva.

Entre las condiciones que también favorecieron la multiplicación de la cultura religiosa material y espiritual afincada en el milagro se encuentran también asuntos como el territorio y las circunstancias a las que se enfrentaban los pobladores. Los rituales practicados permitían al devoto una conexión con la imagen, el santo o la figura de su contemplación. Mediante la repetición constante de ciertos actos se consolidaba una relación o vínculo donde se le otorgaba afecto manifestado en una respuesta o favor más inmediato ante sus peticiones.

\section{Conclusión}

Los milagros tuvieron una cristalización manifestada en las formas de instrumentalización. En el orden de lo espiritual-material se privilegiaron aquellos que sobrepasaban las fuerzas de la naturaleza en cuanto a su modo de obrar, principalmente en el ámbito de la salud-enfermedad donde encontraron una problemática vital para la asistencia; aquí la transmisión requería del relato oral y el testimonio que viajaba de manera doméstica para ganar devotos.

Es posible entonces concluir que una de las claves para la apropiación del milagro fue la relación con el cuerpo, en este caso los actos devocionales tuvieron un papel central porque posibilitaron la incorporación de estos hechos, lo que incrementó la producción de testimonios y conversiones principalmente en el siglo XVIII. Esta lógica también operó para el orden de lo material-espiritual, pero su transmisión se desarrolló mediante la instauración de un discurso-imagen que servía de referente para la construcción de un cuerpo social en el que se orientaban las prácticas devocionales y el control de las mismas. 


\section{Referencias Citadas}

Costilla, J.

2010 El milagro en la construcción del culto a Nuestra Señora de Copacabana (Virreinato del Perú, 1582-1651). En: Estudios Atacameños: Arqueología y Antropología Surandinas. No 39,201 , pp. 35-56.

De Certeau, M. \& Goldstein, V.

2007 El lugar del otro: historia religiosa y mística. Buenos Aires: Katz.

De Mercado, $\mathrm{P}$.

2006 Recetas De Espíritu Para Enfermos Del Cuerpo Por El P. Pedro De Mercado De La Compañía De Jesús (E. Restrepo, Ed.). Bogotá: Universidad Nacional de Colombia.

De Ocáriz J. F.

1943 Genealogías del Nuevo Reino de Granada. Bogotá: Biblioteca Nacional.

De Oviedo, B.

1930 Cualidades y riquezas del Nuevo Reino de Granada: manuscrito del siglo XVIII. Bogotá: Imprenta Nacional.

De Santa Gertrudis, J.

1994 Maravillas de la naturaleza, 1569. Bogotá: Comisión Preparatoria para el V Centenario del Descubrimiento de América. Instituto Colombiano de Cultura.

De Tovar y Buendía, P.

1735 Verdadera histórica relación del origen, manifestación y prodigiosa renovación por sí misma y milagros de la imagen de la sacratissima Virgen María, Madre de Dios Nuestra Señora del Rosario de Chiquinquirá, que está en el Nuevo Reino de Granada. Madrid, por Antonio Marín. En: Biblioteca Nacional de Colombia, colección digital, http://www.bibliotecanacional.gov.co/content/ dos-siglos-de-escritura-en-la-nueva-granada-y-colombiapre\%C3\%A1mbulos-criollos-1630-1740 [15/04/2015].

Le Goff, J.

1999 Lo maravilloso y lo cotidiano en el occidente medieval. Buenos Aires: Altaya.
Lobo Guerrero, B.

1955 Constituciones sinodales, Transcripción de Juan Manuel Pacheco, Eclesiástica Xaveriana.

Marion, J.L.

2006 El cruce de lo visible. Castellón: El Lago Ediciones.

Real Academia Española.

Diccionario de Autoridades, tomo V, 1731.

Romero, M. G.

1960 Fray Juan de los Barros y la evangelización de la Nueva Granada. Biblioteca de Historia Eclesiástica, Bogotá, Academia Colombiana de Historia. En: https://archive. org/stream/frayjuandelosbar00rome\#page/482/mode/2up Recuperado: 01/03/2015, 2:15 pm, p. 483.

Zamora de, F.

1945 Historia de la provincia de San Antonio del Nuevo Reino de Granada, Segunda edición, Bogotá: Biblioteca Popular de Cultura Colombiana, Editorial A B C.

\section{Archivos y fuentes primarias}

Archivo General de la Nación

Sección Colonia, Fondo Milicias y Marina, Legajo 133, F.982 R.AGN. Sección Colonia, Fondo Conventos, Tomo 22. Folios 727-729 R.

AGN

Sección Colonia Fondo Milicias y Marina, Legajo 121, Folio 1017 R.

AGN

Sección Colonia. Fondo Conventos, Tomo 63, folios 489 R.$490 \mathrm{R}$.

Archivo Histórico Regional de Boyacá (AHRB), Tunja.

Fondo Cabildo. Legajo 16 folios 189 R-190 R.

Archivo San Luis Beltrán

Orden de predicadores (ASLOP), Bogotá. MAN. Mariquita, Convento de Sebastián mártir. Serie particulares. Índice 1188. Subserie Miscelánea. Vols. 2/1/3. F 0025R.

\section{Notas}

1 Investigación realizada para obtener el título de Magíster en Historia, 2015.

2 Dentro de las fuentes consultadas son escasas las referencias a negros o esclavos que recibieran milagros, algunos pocos se refieren a la curación de sus males por rogativas hechas por sus amos, pero no es clara la referencia a la posterior conversión como ocurre con la población indígena.

3 Jaime Humberto Borja señala que la lectura reforzaba la predicación y la cultura visual; en sus investigaciones indica la existencia de algunas de las obras que circularon por el Nuevo Reino, como el Flos Sanctorum del jesuita Pedro de Rivadeneira y los 42 libros de vidas de santos y mujeres venerables que permanecían en aquella época en la biblioteca de la Universidad Javeriana (Borja 124).

4 Algunos ejemplos de estos textos que se encuentran publicados son: La Virgen Conquistadora reina de Monguí y Boyacá 1558-1962, un pequeño texto donde se relacionan los momentos claves de la advocación y la Hagiografía de la milagrosa imagen de Nuestra Señora del Rosario de Chiquinquirá escrita por fray Alberto Ariza (comunidad de los dominicos) y publicada en Bogotá en 1950 que se ocupó de describir los acontecimientos milagrosos y el proceso eclesiástico que permitió el reconocimiento de esta imagen por parte del catolicismo oficial.

$5 \quad$ Por medio de los sínodos realizados por los tres primeros arzobispos se formalizaron las prescripciones para la devoción y administración de sacramentos entre los indígenas, oraciones y actos para el destierro de las idolatrías (Lobo Guerrero 1955)

6 La definición más generalizada se relacionaba con la acepción que aparece en el tomo $\mathrm{V}$ del Diccionario de Autoridades, en el que se llama así a "la parte pequeña de alguna cosa sagrada, como de la Cruz de Christo, o de otra qualquiera cosa, que tocasse a su Diviníssimo Cuerpo, o fuesse regada con su preciosa Sangre. Dase también este nombre al pedacito del huesso de algún Santo, u otra qualquiera cosa que por su contacto es digna de veneración" (1731). Sobre la base de esta comprensión descansa buena parte del imaginario eclesiástico que se hizo palpable en la erección o fabricación de los espacios 
al interior de los templos, sobre todo en las provincias cuyos cuerpos sociales estaban más organizados, como ocurre en el caso de la iglesia de San Ignacio de Santafé, analizado por Vilallobos 2012.

7 Es importante señalar que para la época los talleres y artistas criollos empezaban a experimentar con materiales extraídos de la naturaleza, esto generaba cierta duda respecto del comportamiento de los mismos con el paso del tiempo. Aunque se conservaba la estructura de la tradición pictórica, este fue uno de los aspectos en los que más innovaciones aportaron los pintores locales.

$8 \quad$ Las limosnas se pagaban por diversas causas y en diferentes formas: misas, favores, celebraciones, etc.; así, por ejemplo, en 1786 un mayordomo de Popayán presentaba los comprobantes de sus aportes, entre ellos el correspondiente a la limosna pagada por el novenario mandado celebrar por el Cabildo "a la milagrosa imagen del Santo Ecce-Homo, por las muchas aguas que afligían a esta ciudad". Archivo Central del Cauca. Sig.: 5953 (Col. C I-4 dt). Otros documentos de la misma provincia también dan cuenta de los censos realizados a favor de los santos como ocurre en 1777 con la "Escritura por la cual Eusebio López reconoció a censo a favor de "la milagrosa imagen del Dulce nombre de Jesús" Archivo Central del Cauca. 9498 (Col. E 1-12 cap.). De igual manera, las sucesiones también aportan económicamente al culto, adorno y decencia de las imágenes milagrosas y en muchos casos equivalían a exvotos brindados como agradecimiento a los favores recibidos.

9 Acerca de esta sudoración se realiza una asociación con un hecho significativo como la sublevación del Reino de Portugal en el año de 1640 (Flórez de Ocariz Cap. XXIV).

10 Este concepto es utilizado también para definir el uso del milagro en España durante el siglo XVII (Carrasco 401-422). 
